Supplementary Information

For

\title{
Cancer targeted enzymatic theranostic prodrug: Precise diagnosis and chemotherapy
}

Weon Sup Shin, ${ }^{\dagger,}$, Jiyou Han,${ }^{\ddagger}$, Peter Verwilst, ${ }^{\dagger, \S}$ Rajesh Kumar, ${ }^{\dagger}$ Jong-Hoon Kim, ${ }^{\ddagger * *}$ Jong Seung $\operatorname{Kim}^{\dagger} * *$

${ }^{\dagger}$ Department of Chemistry, Korea University, Seoul 136-701, Korea.

Department of Biotechnology, Laboratory of Stem Cells and Tissue Regeneration, College of Life Sciences \& Biotechnology, Korea University, Seoul 136-713, Republic of Korea. 


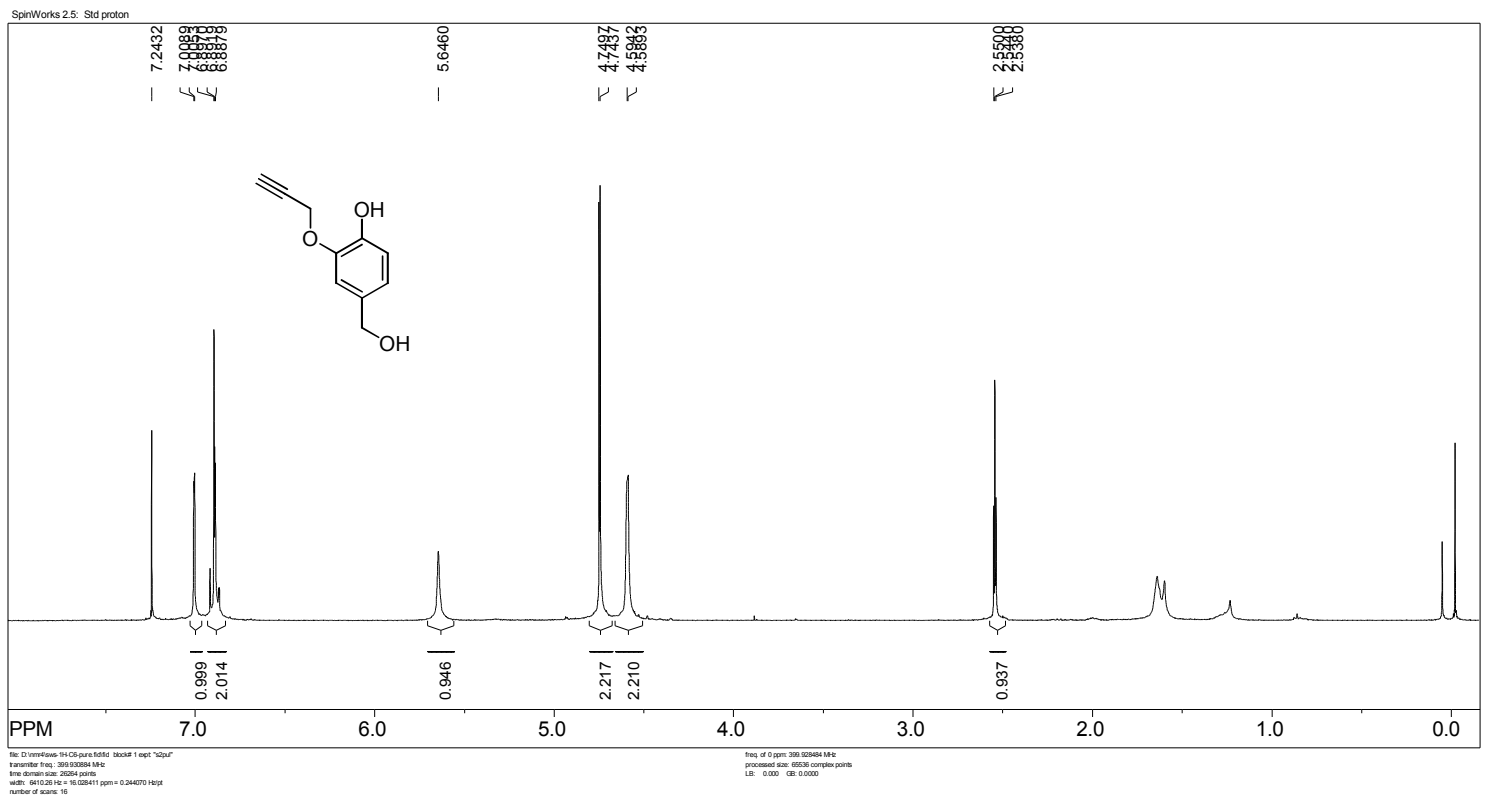

Figure S1. ${ }^{1} \mathrm{H}$ NMR of $\mathbf{6}$

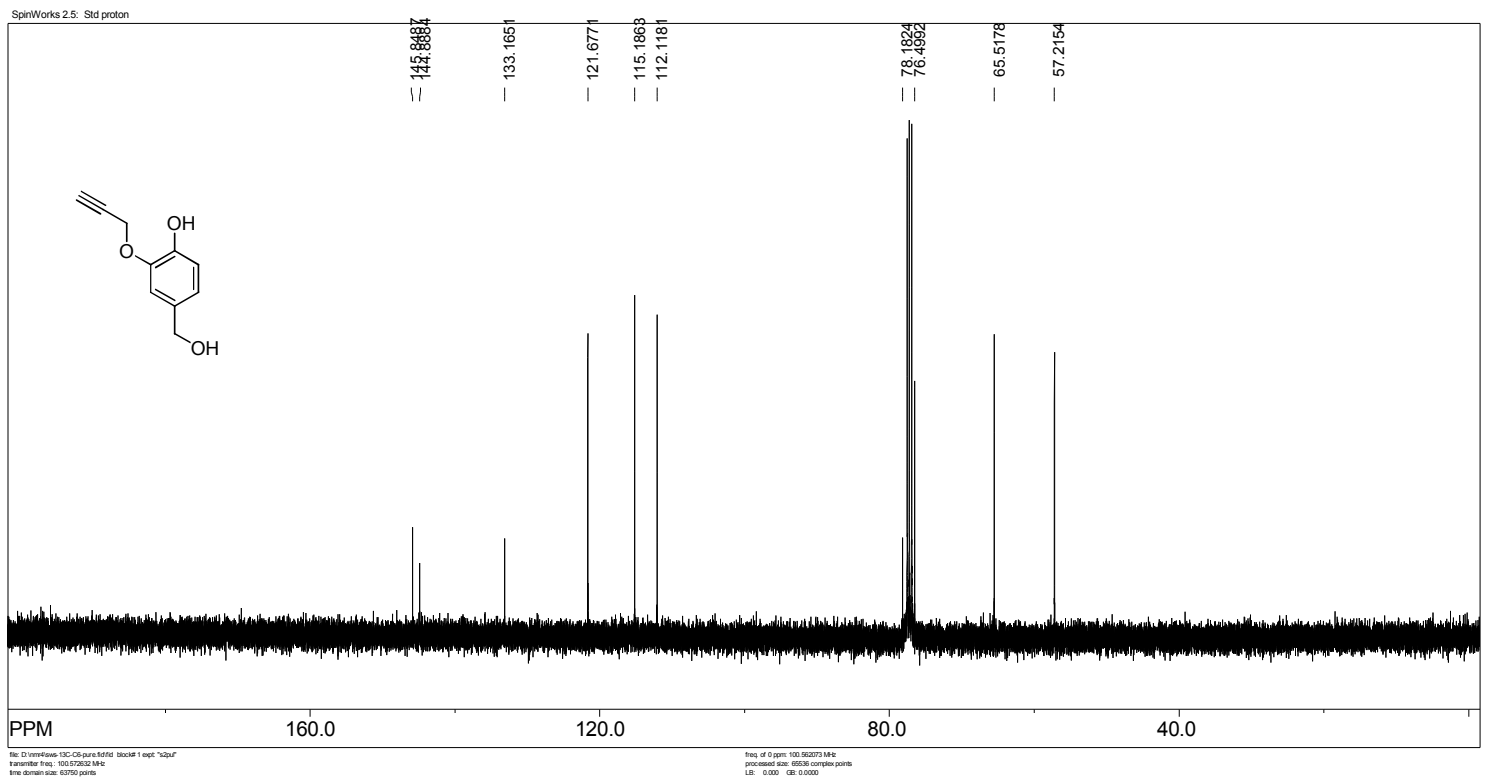

Figure S2 ${ }^{13} \mathrm{C}$ NMR of 6 


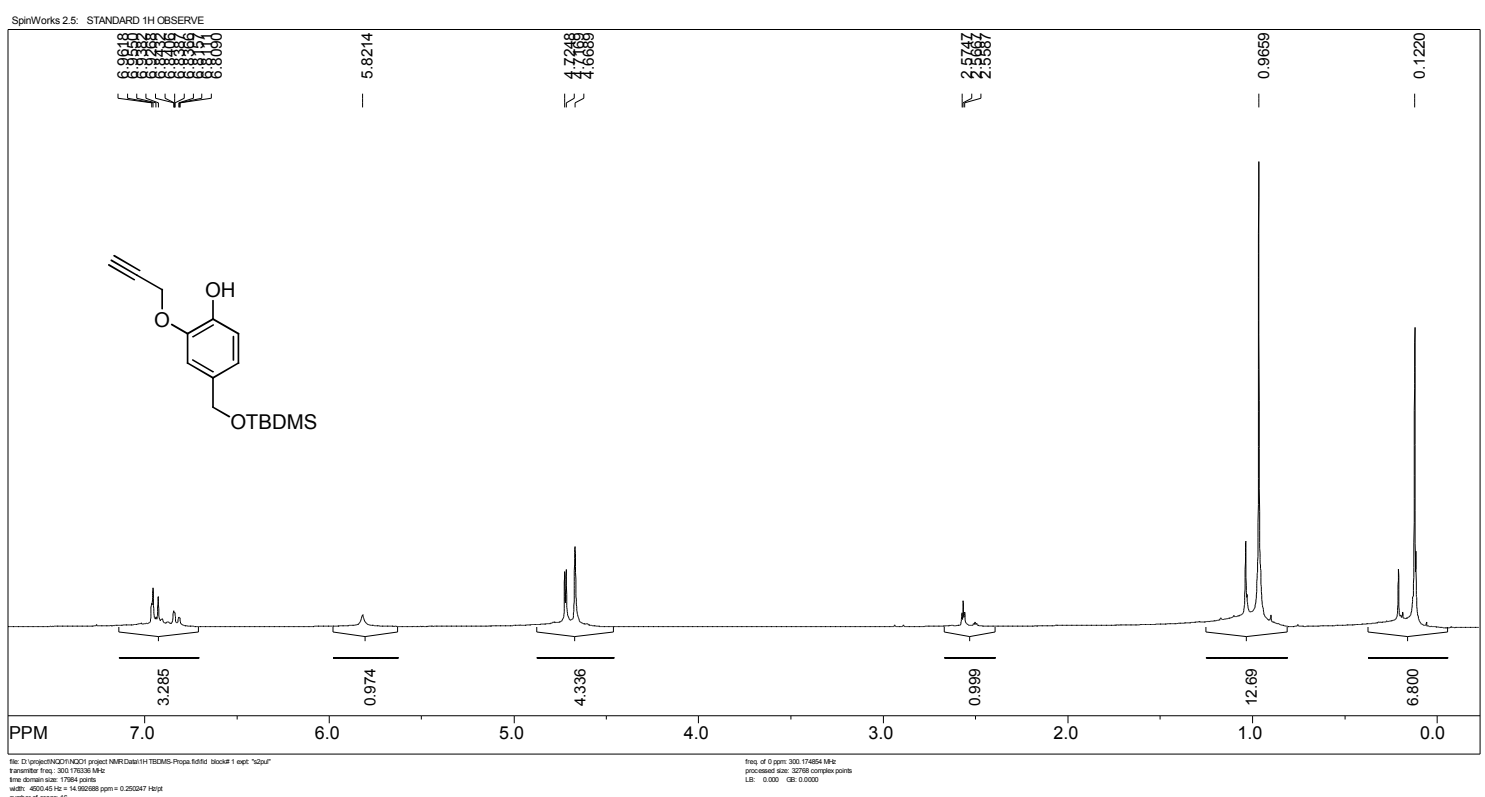

Figure S3. ${ }^{1} \mathrm{H}$ NMR of 5

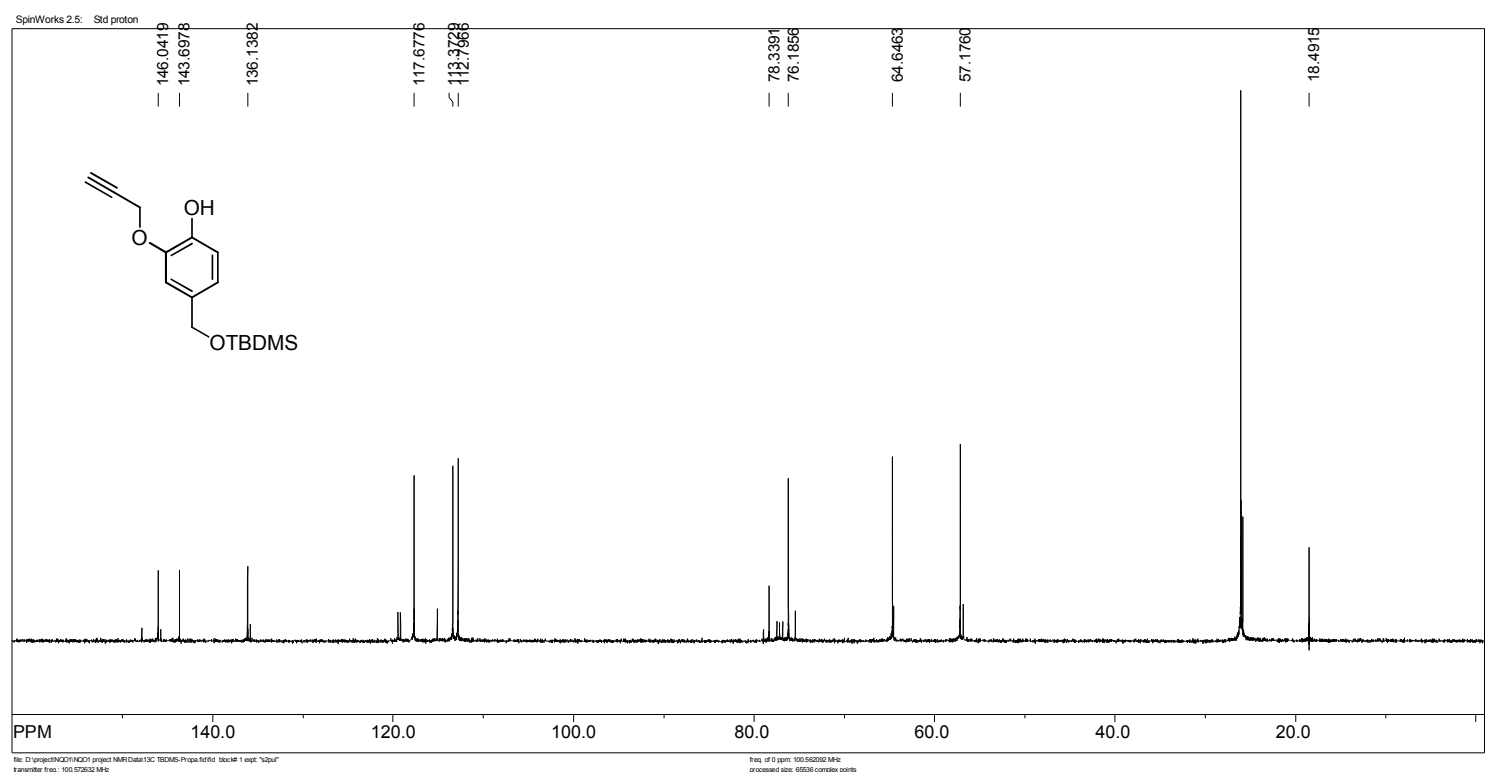

Figure S4. ${ }^{13} \mathrm{C}$ NMR of 5 


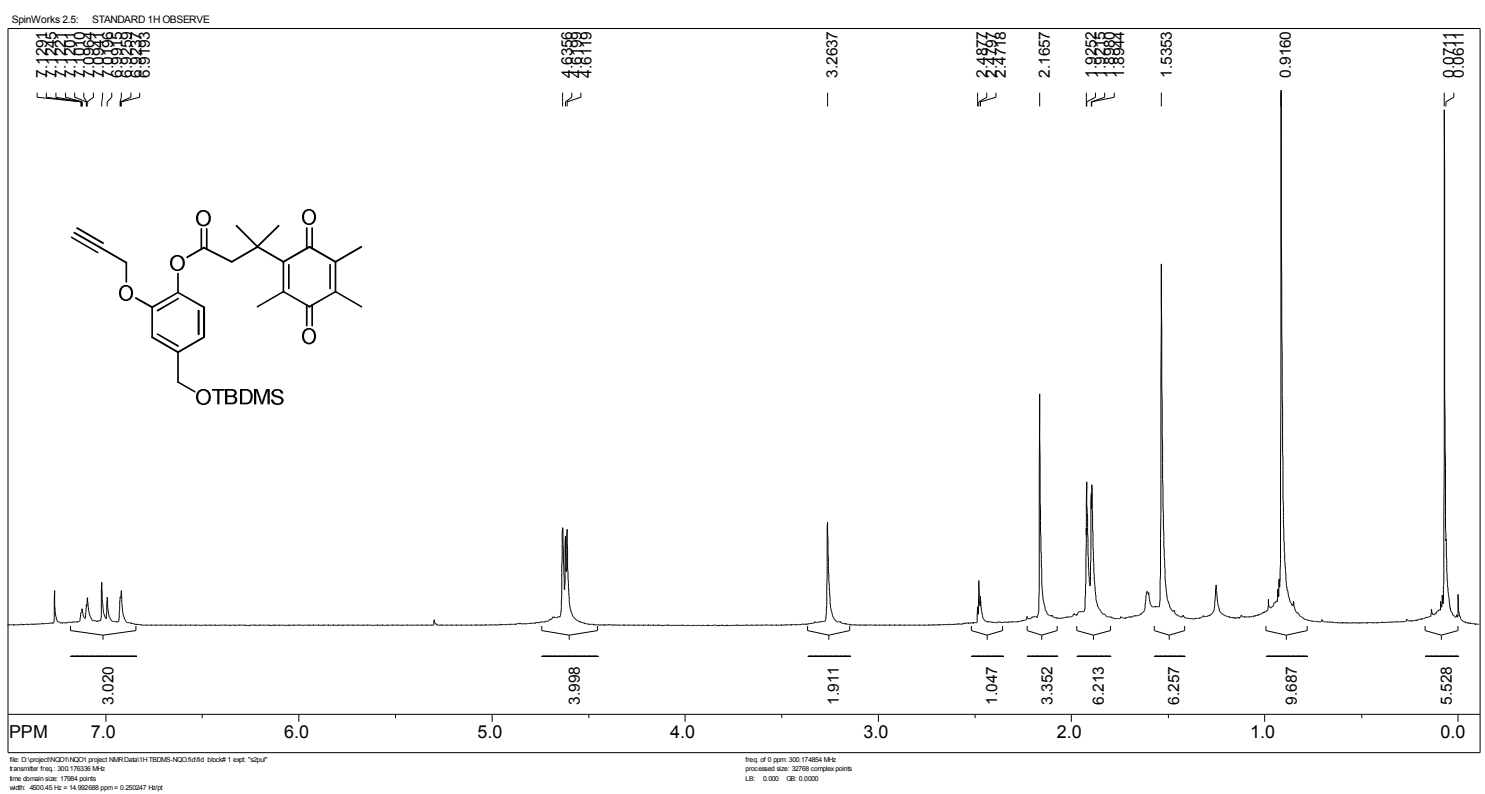

Figure S5. ${ }^{1} \mathrm{H}$ NMR of 4

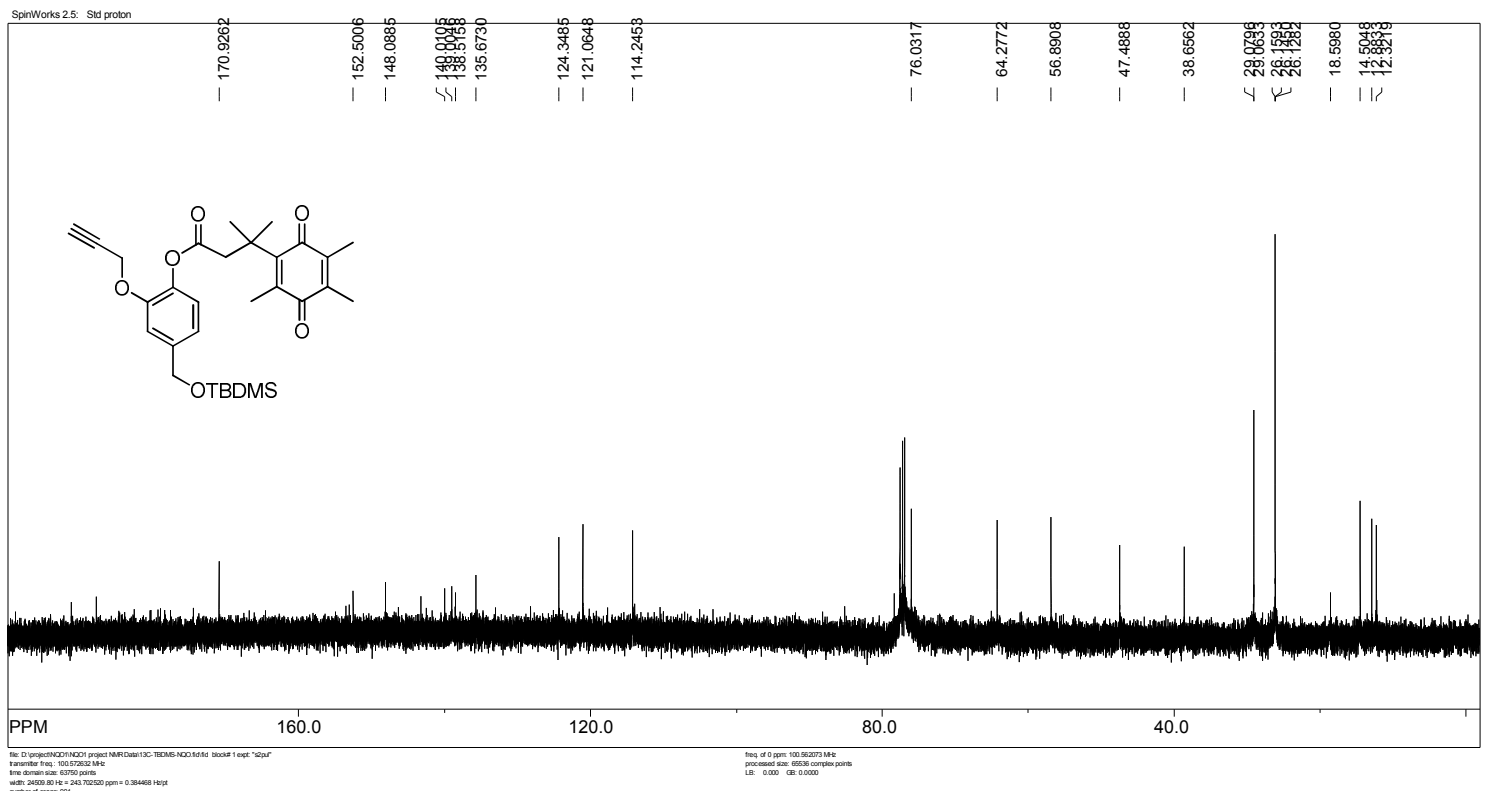

Figure S6. ${ }^{13} \mathrm{C}$ NMR of 4 


\section{$<$ Spectrum >}

Line\#:1 R.Time:0.517(Scan\#:63

MassPeaks: 1001

RawMode:Averaged 0.367-0.783(45-95) BasePeak:605(17323)

BG Mode:None Segment 1 - Event

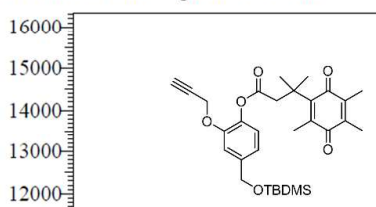

Chemical Formula: $\mathrm{C}_{30} \mathrm{H}_{40} \mathrm{O}_{6} \mathrm{~S}$

11000变 $\quad$ Exact Mass: 524.26

9000

8000

7000

6000

5000

4000

3000

200

000棒

480
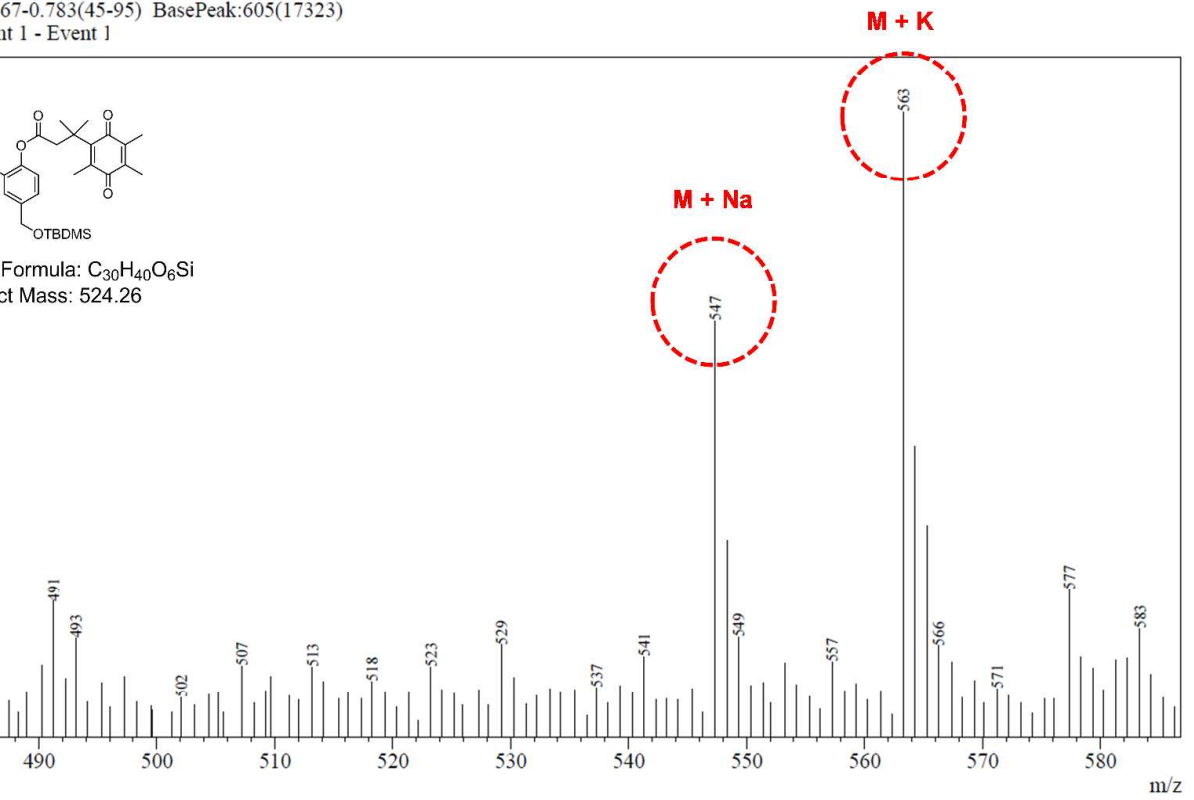

Figure S7. Mass spectrum of $\mathbf{4}$

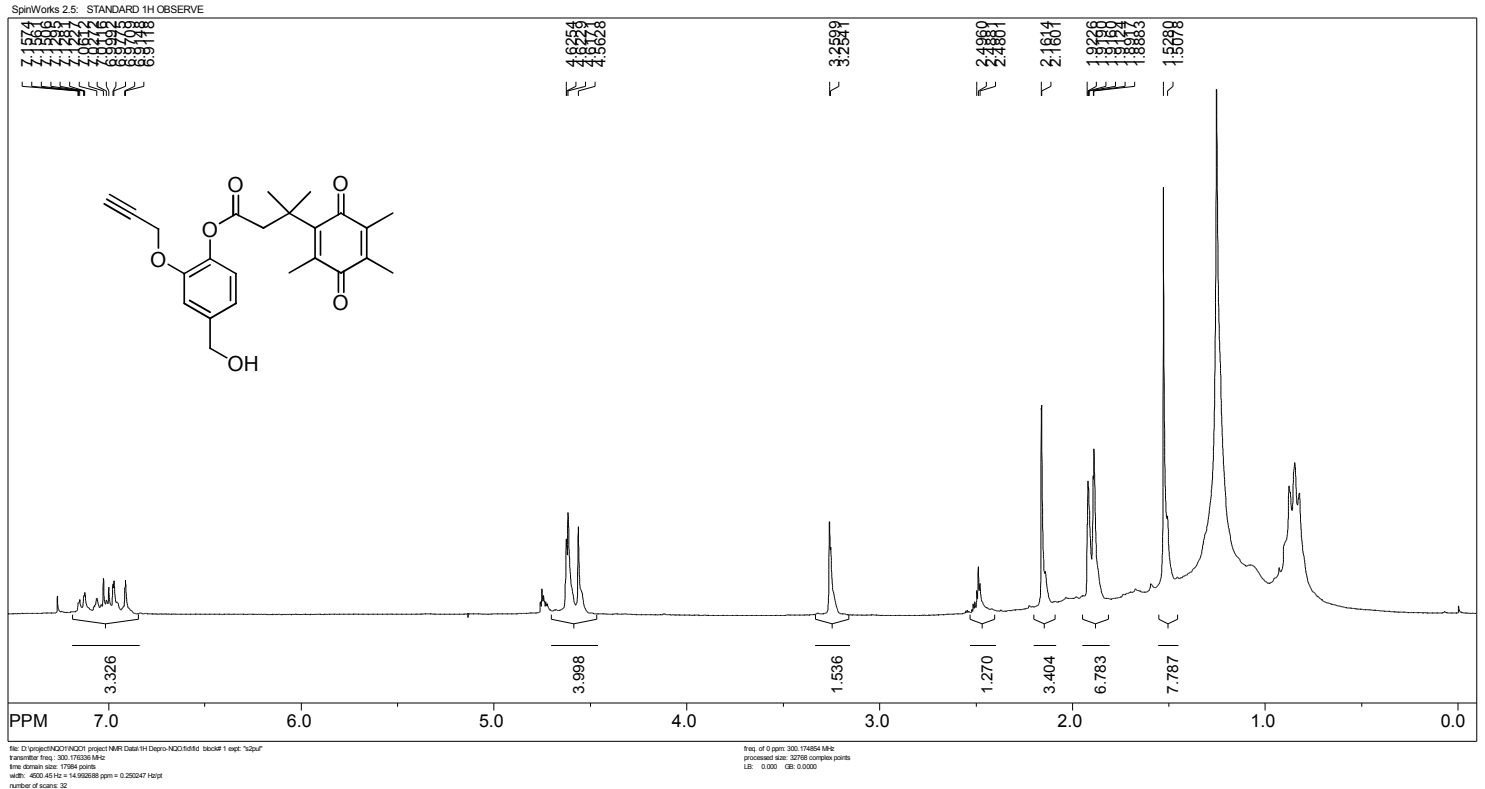

Figure S8. ${ }^{1} \mathrm{H}$ NMR of 3 


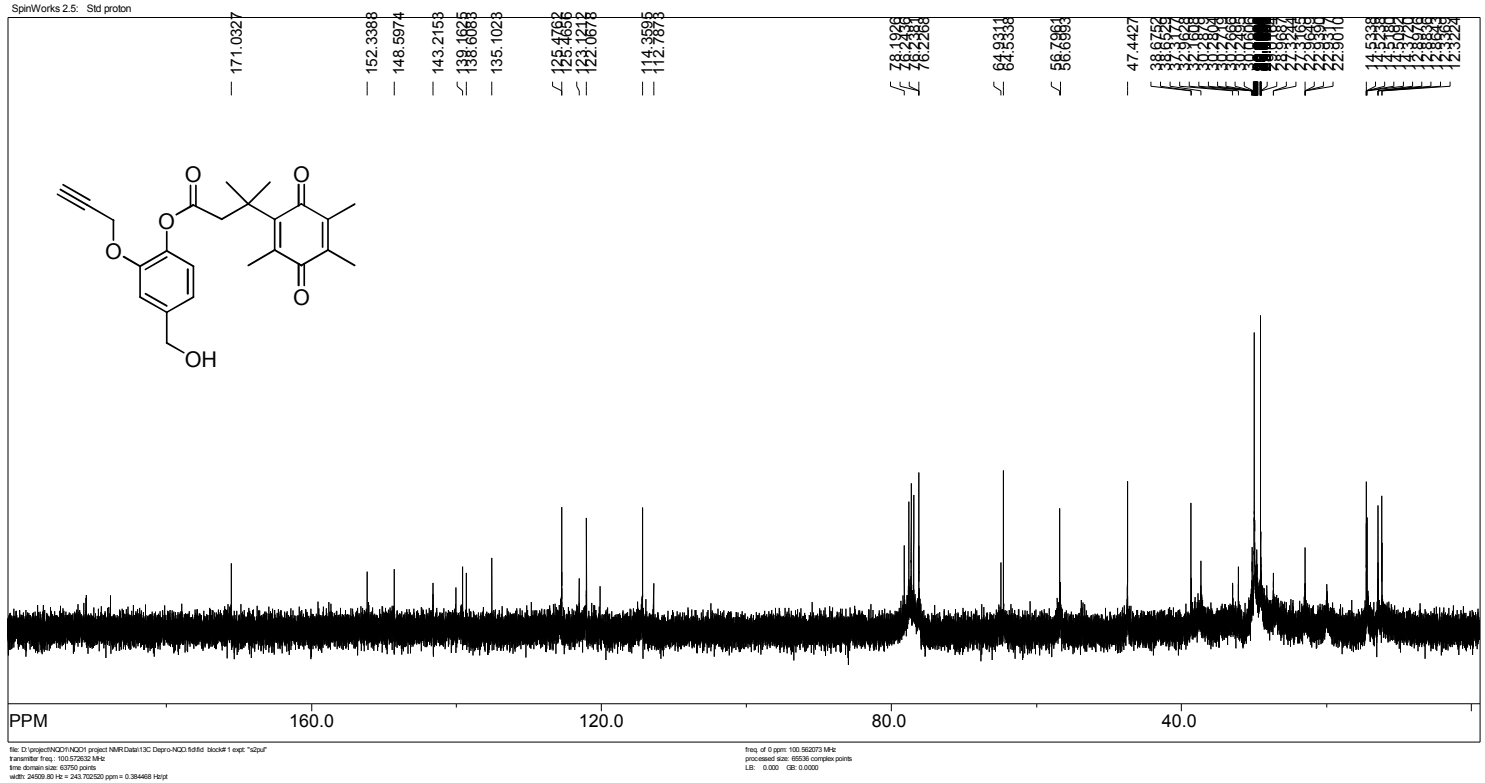

Figure S9. ${ }^{13} \mathrm{C}$ NMR of $\mathbf{3}$

\section{$<$ Spectrum>}

Line\#:1 R.Time:0.550(Scan\#:67

MassPeaks: 1072

RawMode:Single 0.550(67) BasePeak:605(43528

BG Mode:None Segment 1 - Event

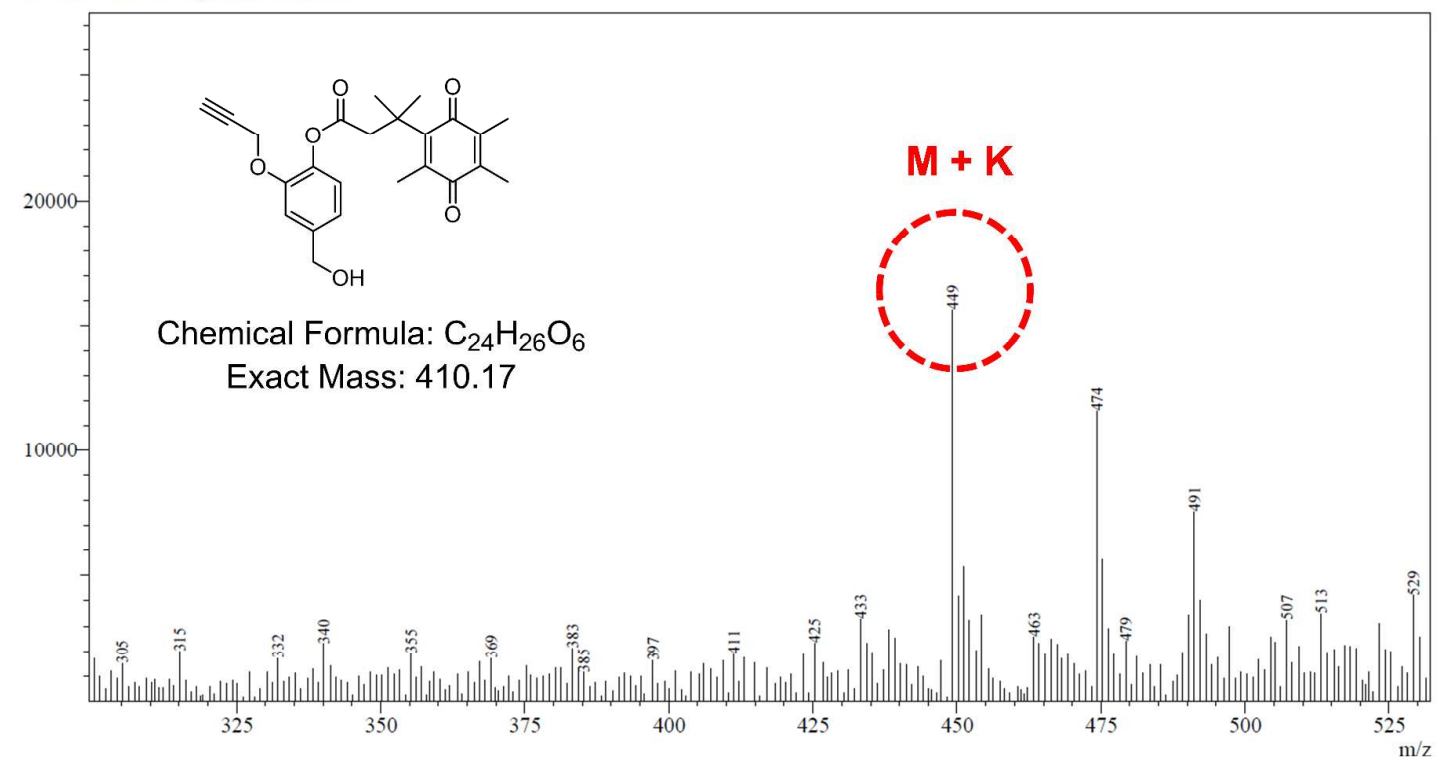

Figure S10. Mass spectrum of $\mathbf{3}$ 


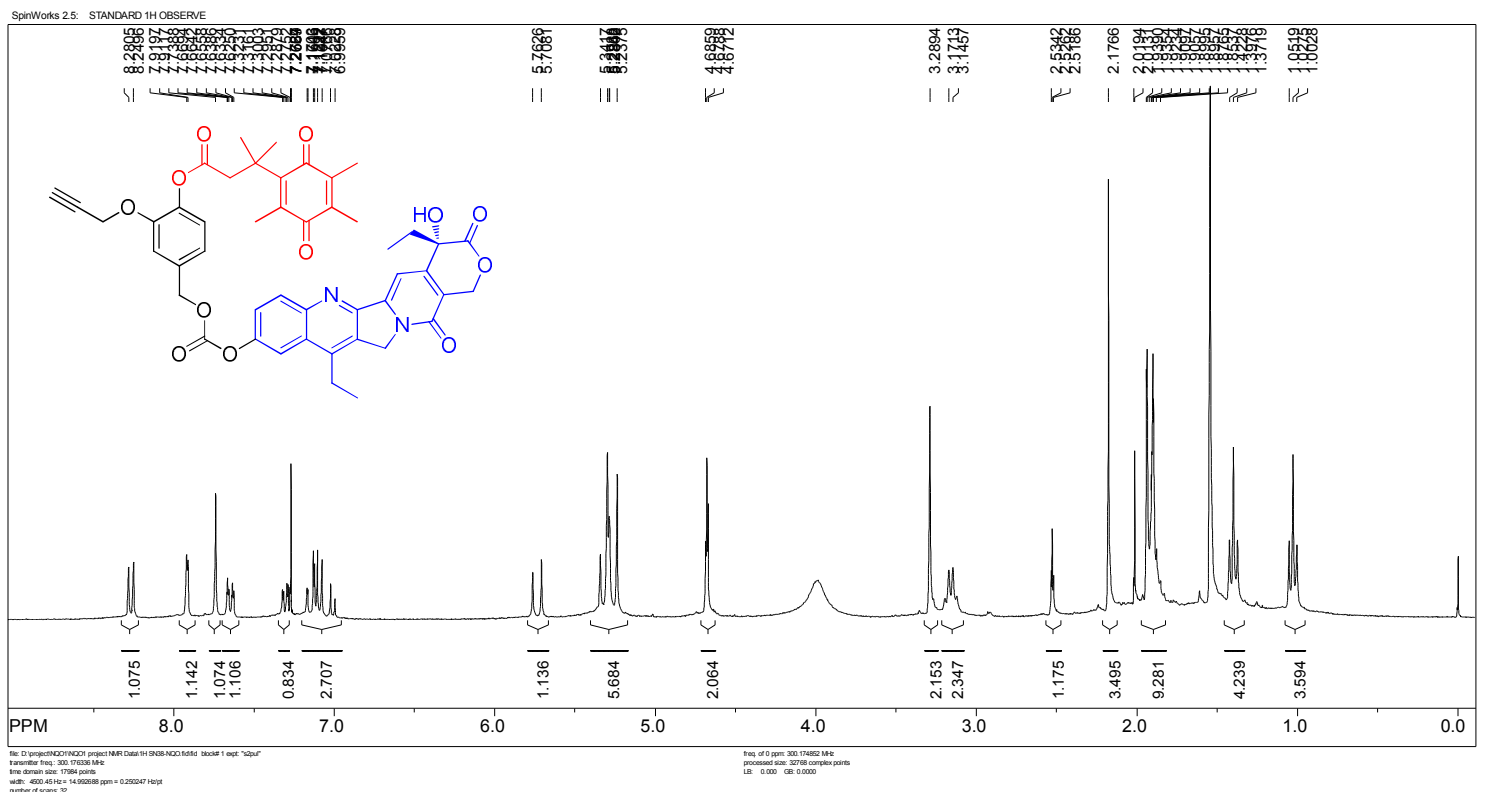

Figure S11. 1H NMR of $\mathbf{2}$

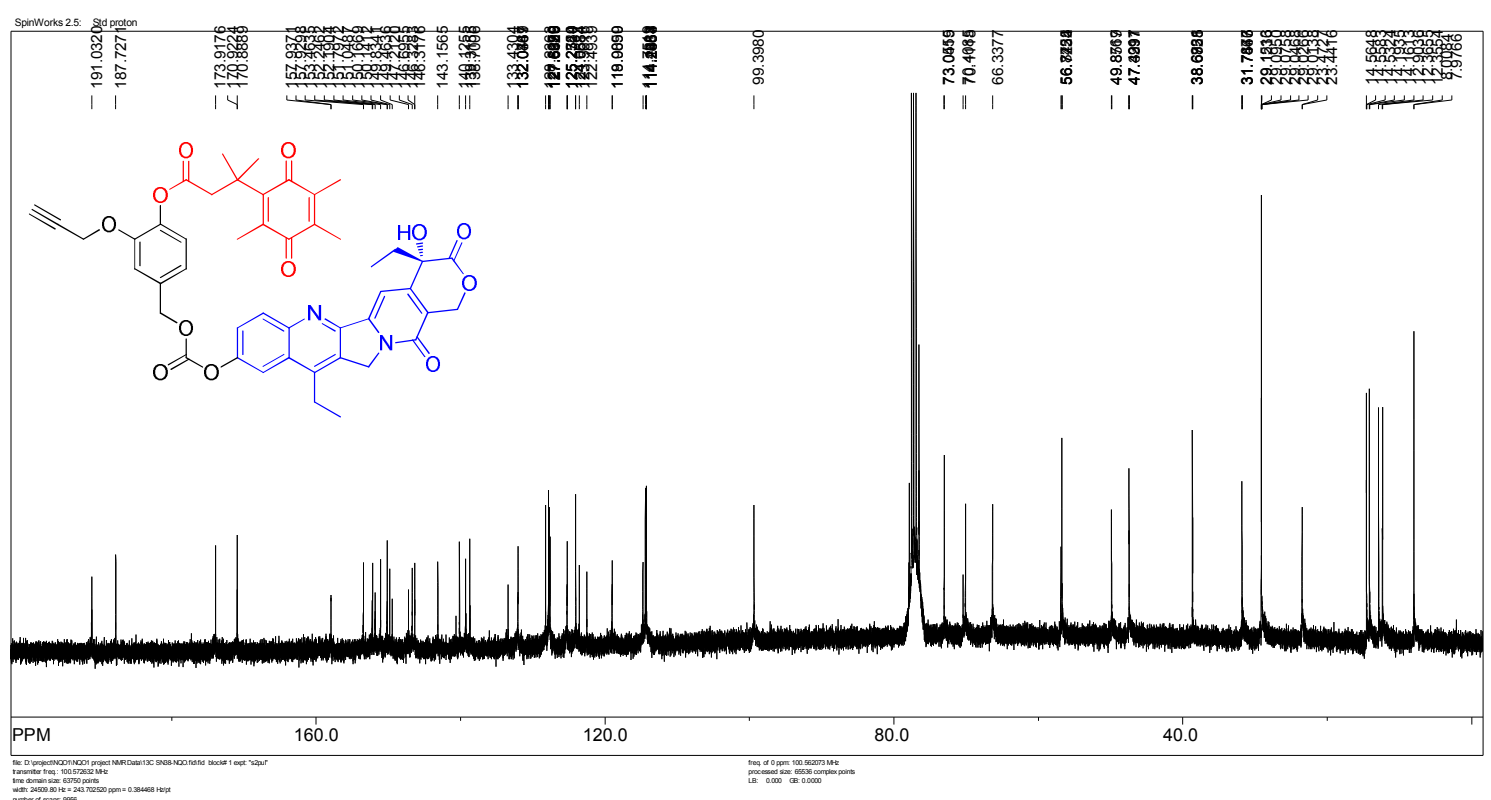

Figure S12. ${ }^{13} \mathrm{C}$ NMR of $\mathbf{2}$ 


\section{$<$ Spectrum $>$}

Line\#:1 R.Time: 0.500 (Scan\#:61

MassPeaks: 1101

RawMode:Averaged 0.400-0.700(49-85) BasePeak:220(29038)

BG Mode:None Segment 1 - Event ]

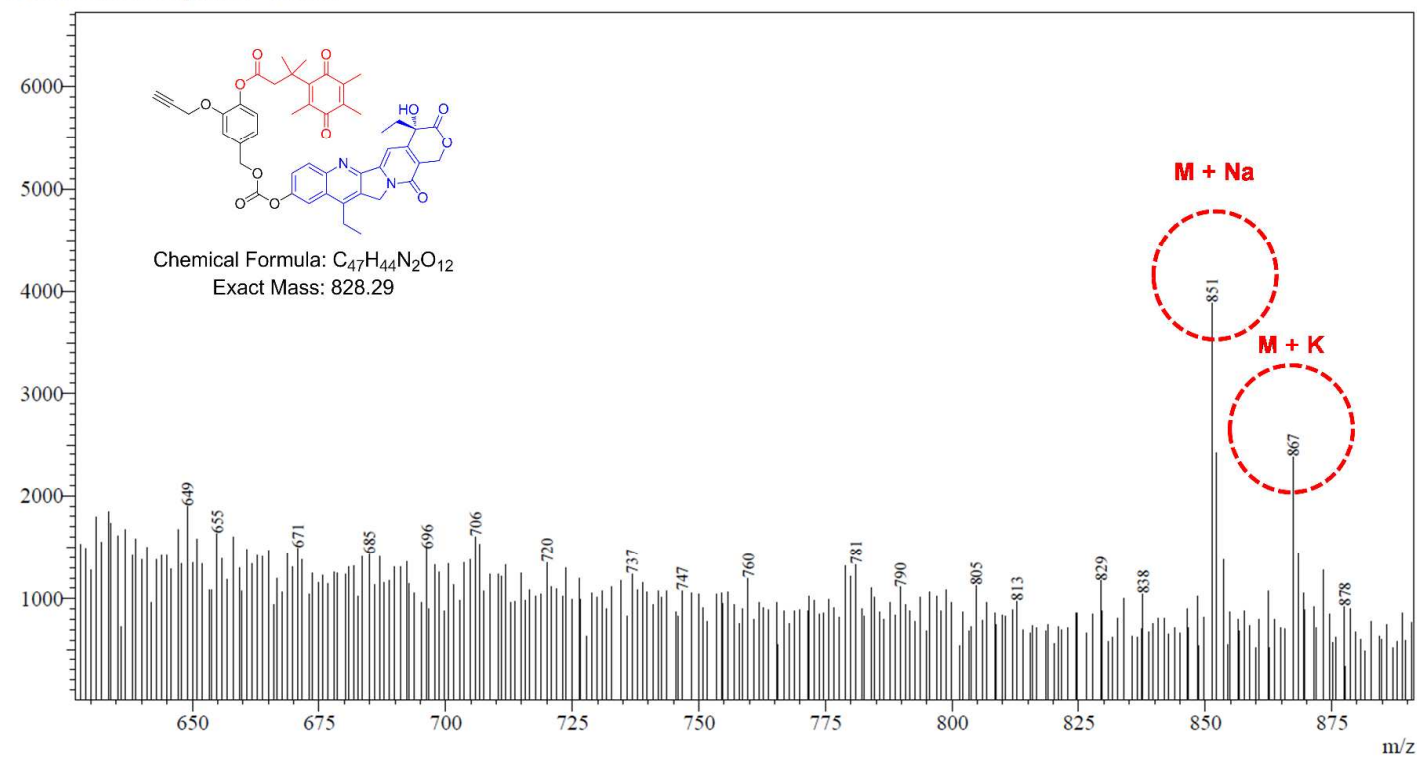

Figure S13. Mass spectrum of 2

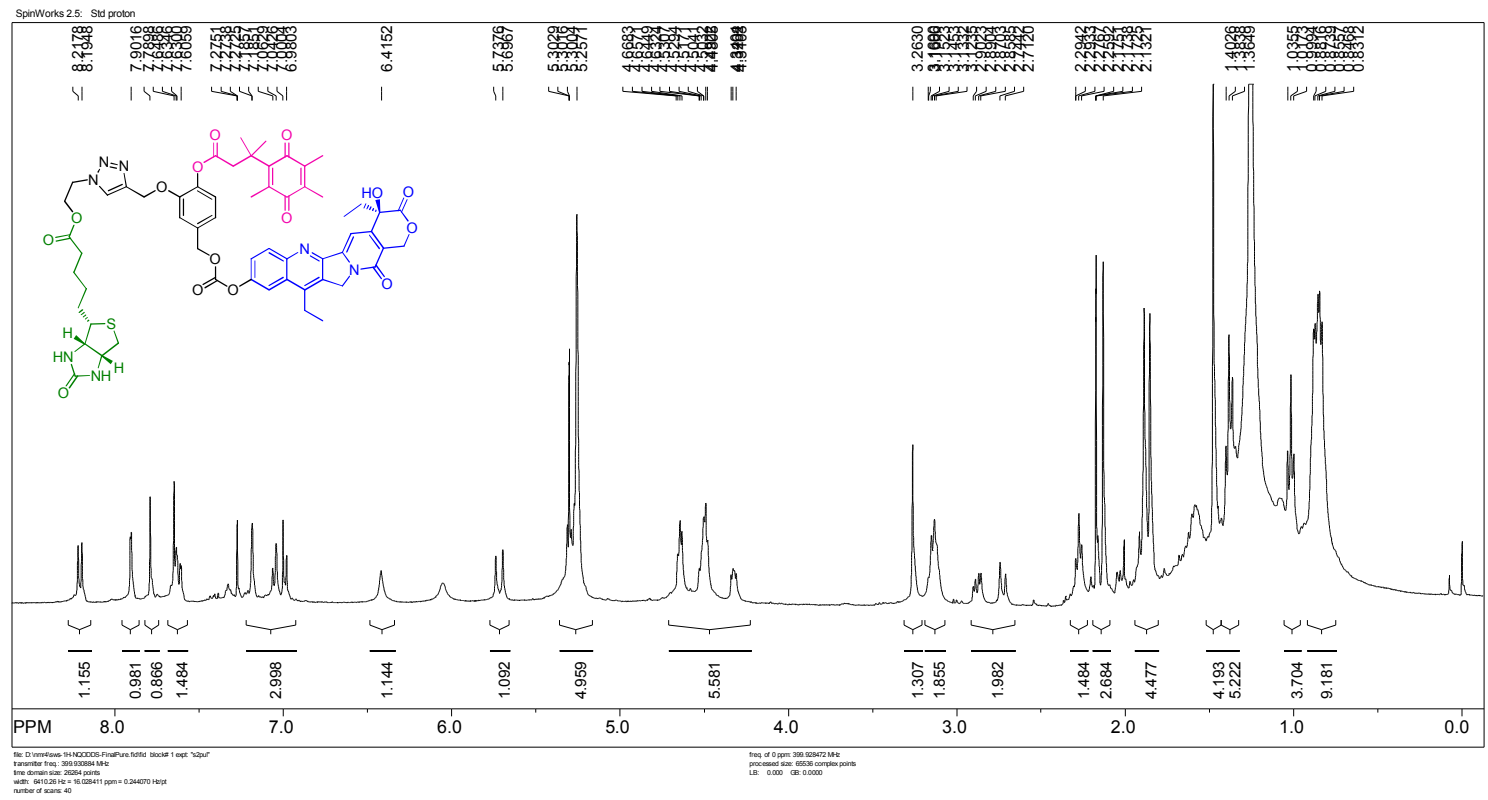

Figure S14. ${ }^{1} \mathrm{H}$ NMR of $\mathbf{1}$ 


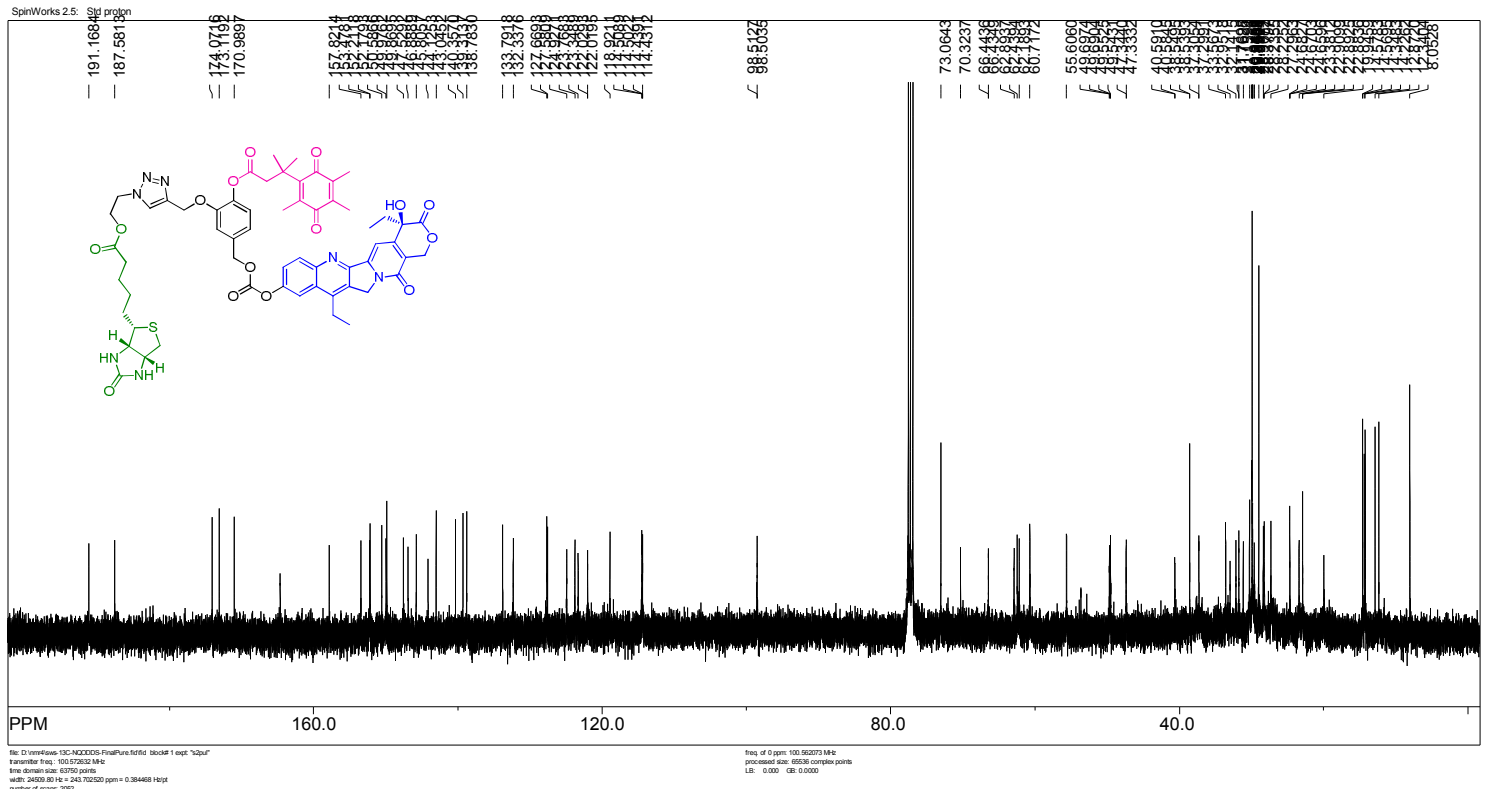

Figure S15. ${ }^{13} \mathrm{C}$ NMR of $\mathbf{1}$

\section{$<$ Spectrum >}

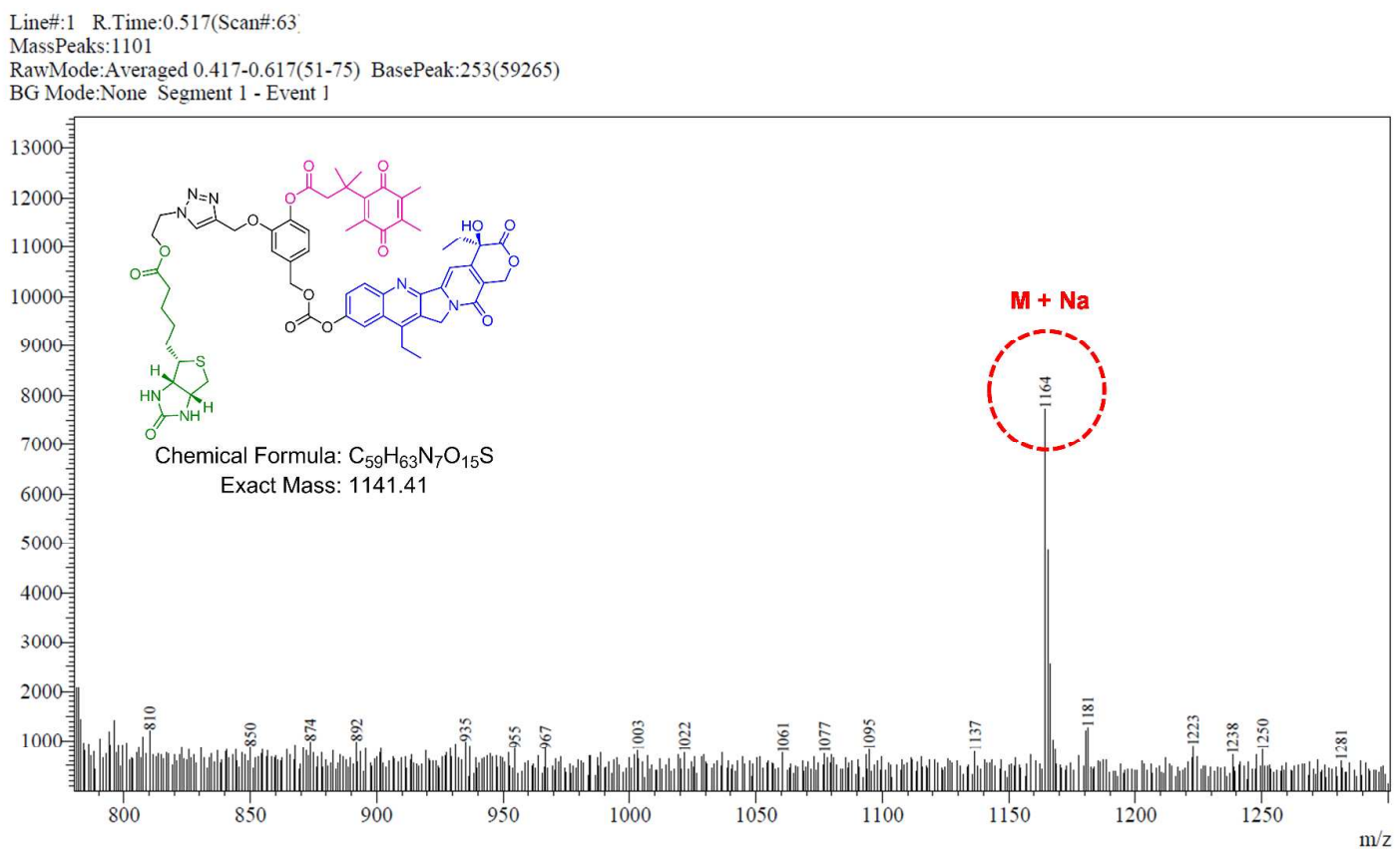

Figure S16. Mass spectrum of $\mathbf{1}$ 


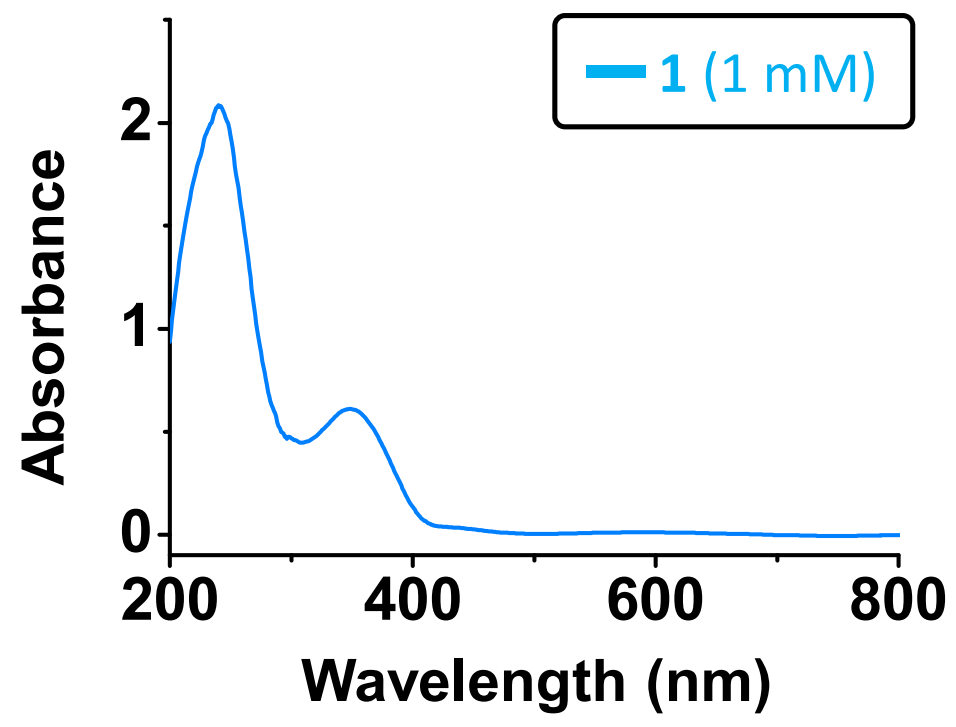

Figure S17. UVVis spectrum of $\mathbf{1}(1 \mathrm{mM})$.

(a)

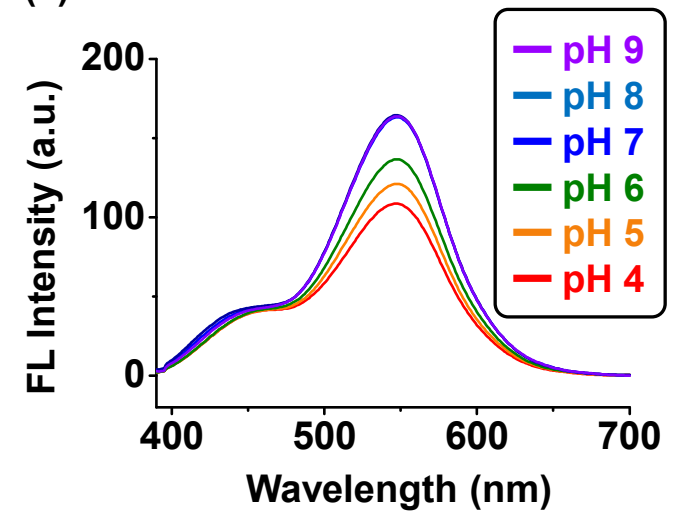

(b)

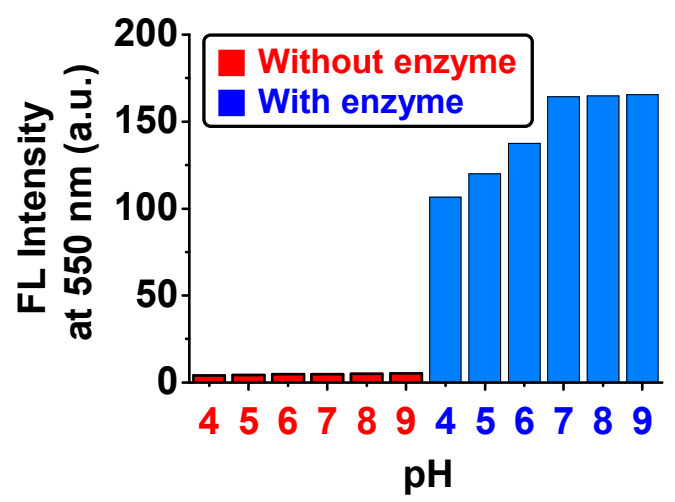

Figure S18. (a) Fluorescence response of $1(10 \mu \mathrm{M})$ in the presence of NADPH $(100 \mu \mathrm{M})$ and NQO1 $(20 \mu \mathrm{g} / 2 \mathrm{~mL})$ at various $\mathrm{pH}$ values at $25^{\circ} \mathrm{C}$ after $2 \mathrm{~h}$. (b) Stability test of $\mathbf{1}(10 \mu \mathrm{M})$ in the presence of NADPH $(100 \mu \mathrm{M})$ with enzyme (blue) and without NADPH and enzyme (red) $(20 \mu \mathrm{g} / 2 \mathrm{~mL})$ at $25^{\circ} \mathrm{C}$ for $2 \mathrm{~h}$. 
(a)

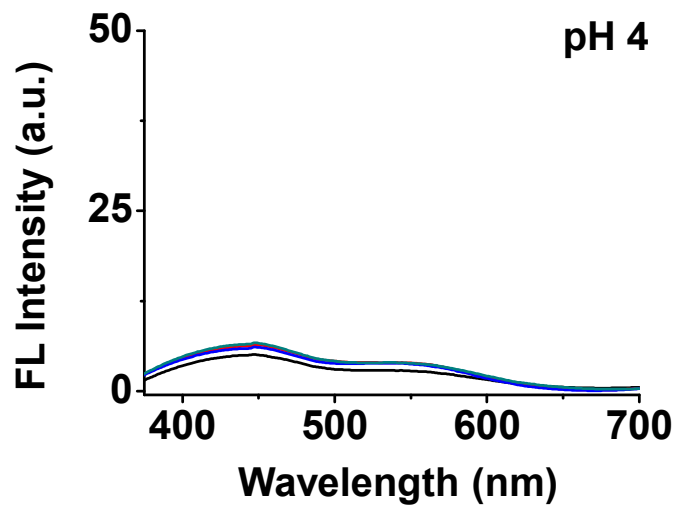

(c)

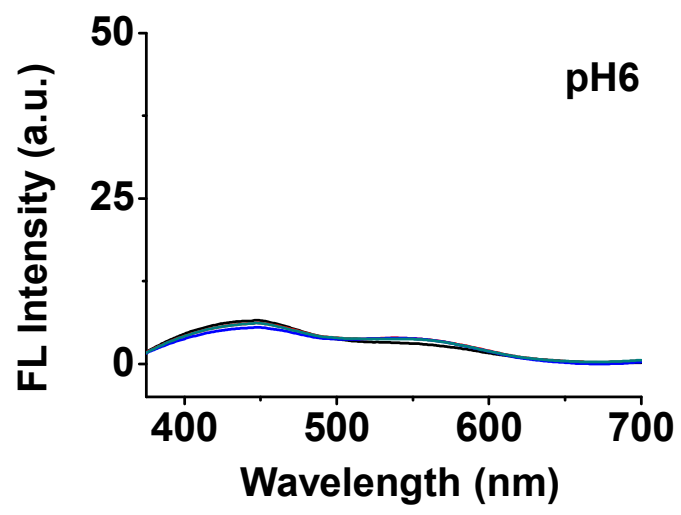

(e)

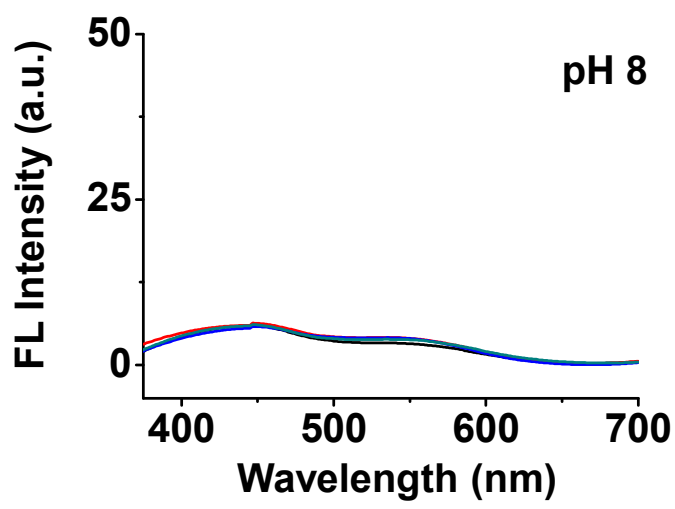

(b)

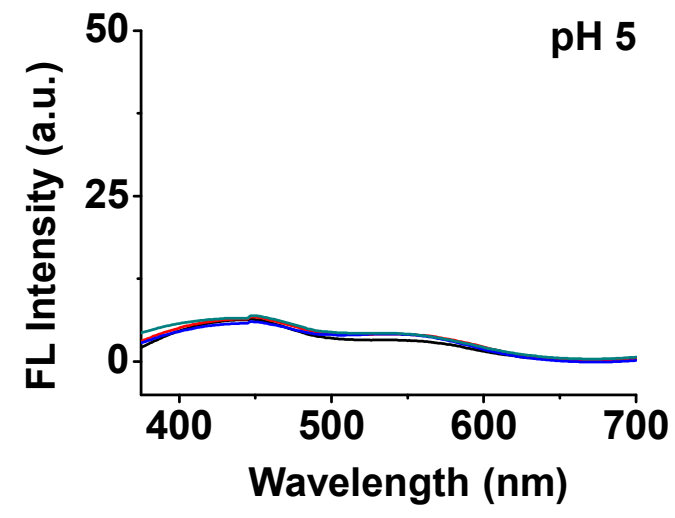

(d)

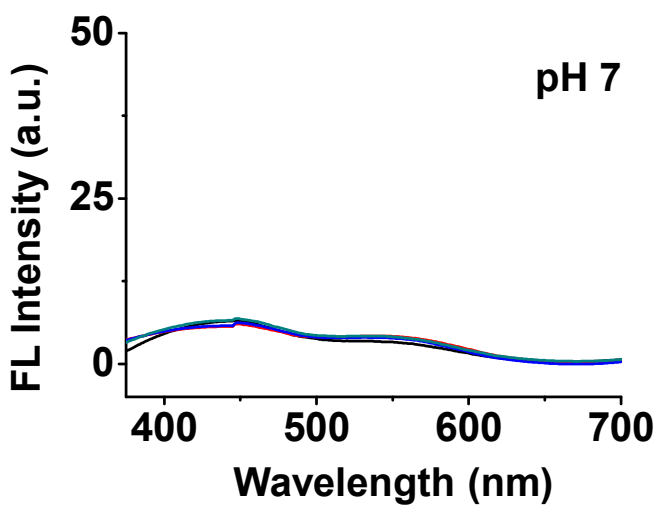

(f)

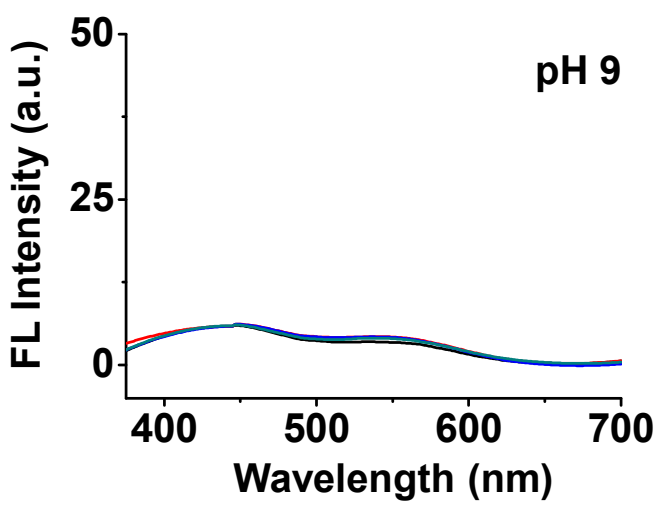

Figure S19. Stability of $\mathbf{1}(10 \mu \mathrm{M})$ at various $\mathrm{pH}$ values in PBS solution at $\left.25^{\circ} \mathrm{C}\right)$ over the course of $2 \mathrm{~h}$. Data were recorded at 30 minutes interval 
(a)
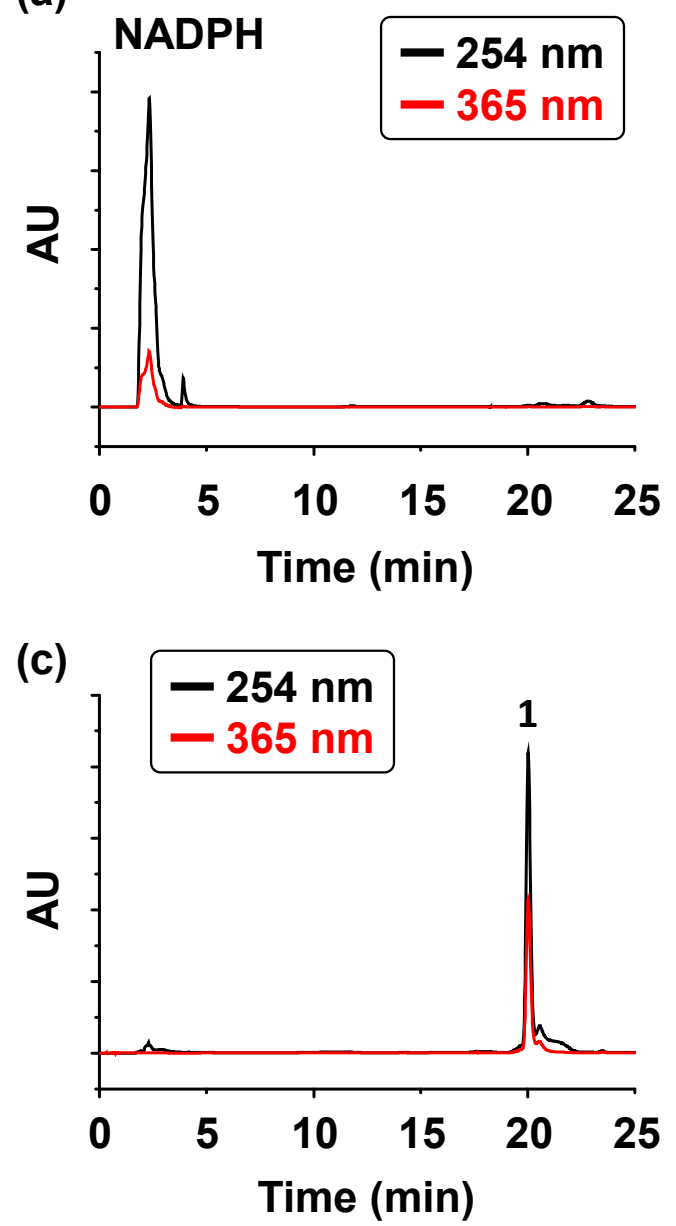

(b)

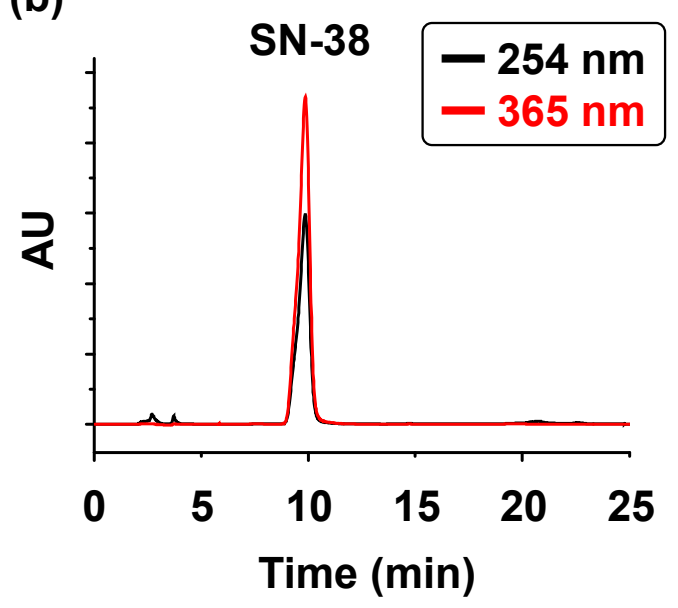

(d)

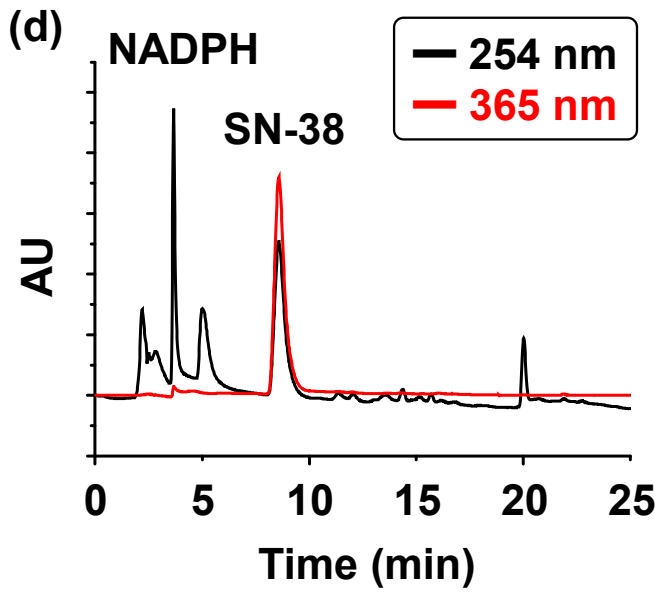

Figure S20. HPLC traces of (a) NADPH, (b) SN38, (c) 1, (d) 1 with NADPH and NQO1 enzyme. ACN 30\% to $70 \%$ during $17 \mathrm{~min}, 100 \% \mathrm{ACN} 17 \mathrm{~min}$ to $25 \mathrm{~min}$. 
Table S1. Primer information used in RT-PCR analysis.

\begin{tabular}{|c|c|c|c|}
\hline $\begin{array}{c}\text { Name of } \\
\text { gene }\end{array}$ & Forward primer sequence & Reward primer sequence & $\begin{array}{c}\text { Annealing } \\
\mathbf{T}_{\mathbf{m}}\left({ }^{\circ} \mathbf{C}\right) \\
\text { product } \\
\text { size (bp) }\end{array}$ \\
\hline TOP1 & CAA GCA GCC CGA GGA TGA TC & GCA CTT TTC AGG TCT CTC CG & $58(333)$ \\
\hline MRP2 & ACAGAGGCTGGTGGCAAC C & GGGACCCTGCGCATGAACCTG & $56(348)$ \\
\hline BCRP & AGT TCC ATG GCA CTG GCC ATA & TCA GGT AGG CAA TTG TGA GG & $59(379)$ \\
\hline BAX & GGACCCGTTCCTGGTGCTGC & GTCTAGGCCGCTCTGCACGC & $60(130)$ \\
\hline Caspase-3 & TGGTGTTGATGATGACATGGCGTG & AGCATGGCACAAAGCGACTGGA & $60(130)$ \\
\hline Caspase-9 & TCGAGGACATCCAGCGGGCA & GCCAGCATGTCCTGGCCTGT & $60(130)$ \\
\hline GAPDH & GAGGTTGGCTCTGACTGTACC & TCCGTCCCAGTAGATTACCAC & $60(130)$ \\
\hline
\end{tabular}

